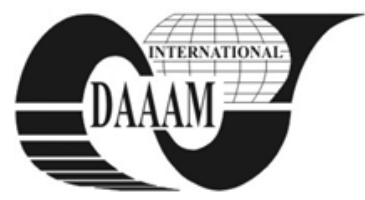

Annals of DAAAM for 2011 \& Proceedings of the 22nd International DAAAM Symposium, Volume 22, No. 1, ISSN 1726-9679 ISBN 978-3-901509-83-4, Editor B. Katalinic, Published by DAAAM International, Vienna, Austria, EU, 2011 Make Harmony between Technology and Nature, and Your Mind will Fly Free as a Bird

Annals \& Proceedings of DAAAM International 2011

\title{
INFLUENCE OF DEFORMATION INDUCED MARTENSITE ON BRITTLENESS OF AUSTENITIC STAINLESS STEEL
}

\author{
JURAGA, I[van]; ALAR, V[esna]; SIMUNOVIC, V[inko] \& STOJANOVIC, I[van]
}

\begin{abstract}
Austenitic Cr-Ni stainless steels are an important group of construction materials owing to their good mechanical and corrosion resistance properties. However, as a consequence of plastic deformation, for instance cold forming, a transformation of their single phase austenitic structure may arise which results in formation of deformation induced martensite. The consequences are significant loss of their mechanical properties, brittleness and fracture. This paper shows the case study of real damages caused by deformation induced martensite phenomena.
\end{abstract}

Key words: austenitic stainless steel, deformation induced martensite, brittleness

\section{INTRODUCTION}

Austenitic Cr-Ni corrosion resistance steels are a dominant group of stainless steels which are extensively applied in different fields thanks to their good mechanical properties, in particular high toughness and properties retention even when applied at low temperatures. At the same time, because of their spontaneous passivity based on a thin chromium oxide film formation on the surface, austenitic stainless steels have high corrosion resistance properties (Davis, 1994; Sedriks, 1996). These steels usually contain a very low share of carbon, and are alloyed with minimum $16 \%$ of Chromium and sufficient content of Nickel (more than $8 \%$ ) to ensure a single phase austenitic microstructure. However, as a consequence of cold deformation (e.g. metal forming process), microstructural changes and deformation induced martensite occurs which has a great influence on mechanical properties - increase of hardness and significant decrease of toughness which results in a very dangerous brittleness. At the same time, non-magnetic austenitic steel becomes slightly ferromagnetic (Kurc \& Stoklosa, 2010; Meszaros \& Prohaszka, 2005; Ozgowicz et al., 2010).

\section{CASE HISTORIES OF DEFORMATION INDUCED MARTENSITE EFFECT}

During exploitation, sometimes in just a couple of months, intensive damages of electric heaters have occurred which disabled their further application and demanded their sequential replacement. Heaters were made from seamless pipes $(\varnothing 12 \mathrm{~mm}$ $\times 1 \mathrm{~mm}$ ) from austenitic stainless steel grade W. Nr. 1.4571 and formed to required shape by cold forming process. Stereomicroscopic images of occurred damages are shown in Figures 1 and 2, where a longitudinal crack is visible as well as destruction of metal by melting resulting from short circuits which were created during the operation of heaters. After detailed visual inspection and damage analysis it is concluded that morphologic properties of damages as well as their almost in-line arrangement on the surface of the heaters do not indicate a relation to pitting corrosion, but rather that the resulting damages were exclusively influenced by electric current.

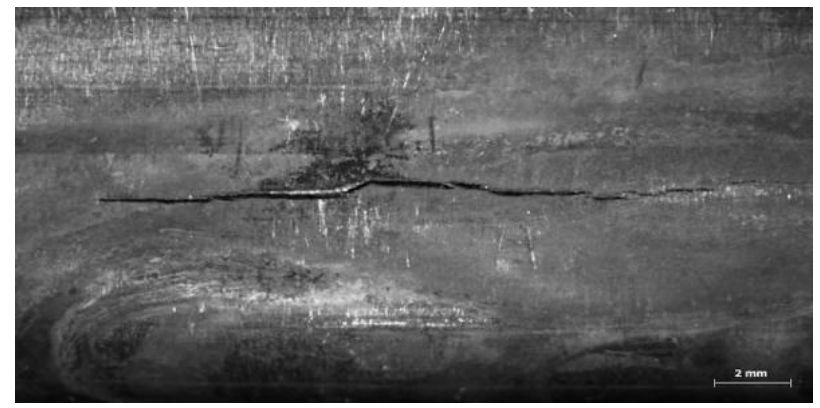

Fig. 1. Characteristic longitudinal crack formed on the heater during exploitation

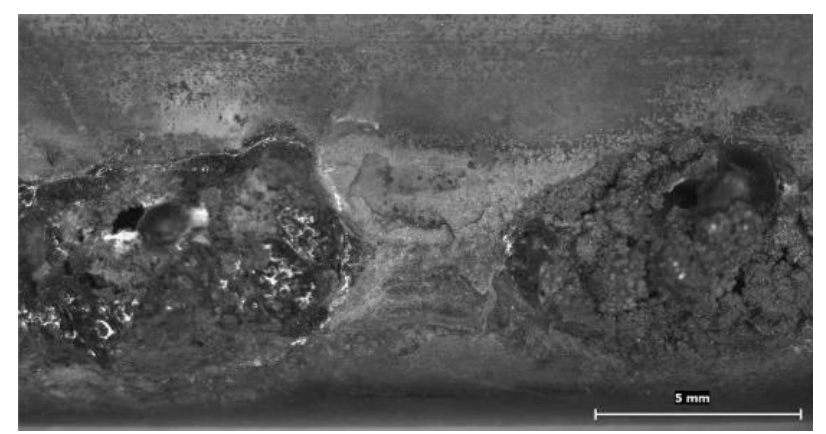

Fig. 2. Melting destruction of the metal due to short circuit

\section{CONDUCTED TESTING}

\subsection{Radiographic testing}

Radiographic testing was carried out on the heater damaged during exploitation, as well as on the heater which hasn't been in use, Figure 3. In-line arrangement of damages in the area above the heating coil is clearly visible.

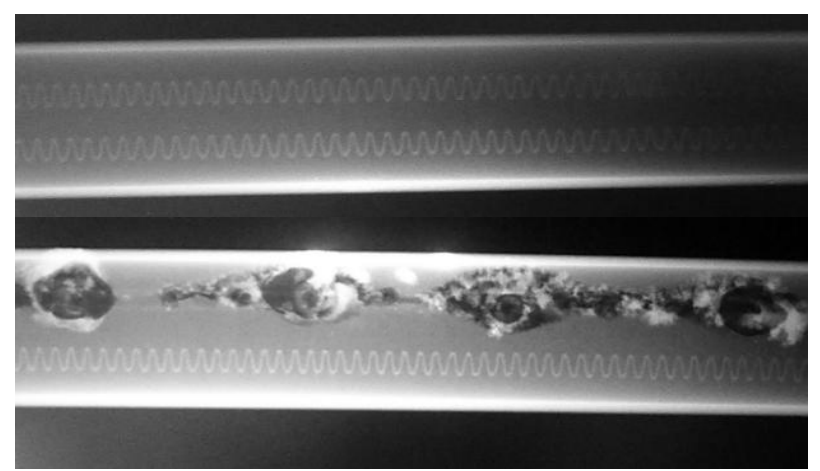

Fig. 3. Radiogram of the heater before (up) and after exploitation (down) with visible distribution of damages 


\subsection{Microhardness testing}

Microhardness testing was carried out by Vickers method (HV1) according to EN ISO 6507-1 standard on the base material sample - pipe and on the sample of formed heater. Testing results are given in Table 1.

The testing results show a significant increase of microhardness on the sample which is formed by cold forming process (sample of the heater) in comparison to the base material - pipe from which the heaters are formed.

\begin{tabular}{|c|c|c|c|c|c|}
\hline \multicolumn{2}{|c|}{ Sample } & \multicolumn{2}{c|}{ Pipe } & \multicolumn{2}{c|}{ Heater } \\
\hline \multicolumn{2}{|c|}{ Measurement } & $d, \mathrm{~mm}$ & HV1 & $d, \mathrm{~mm}$ & HV1 \\
\hline \multirow{3}{*}{$\begin{array}{c}\text { Location } \\
1\end{array}$} & 1 & 0.107 & 162 & 0.0775 & 309 \\
\cline { 2 - 6 } & 2 & 0.111 & 151 & 0.0780 & 305 \\
\cline { 2 - 6 } & 3 & 0.106 & 165 & 0.0770 & 313 \\
\hline \multicolumn{3}{|c|}{ AVERAGE } & $\mathbf{1 5 9 , 3}$ & AVERAGE & $\mathbf{3 0 9 . 0}$ \\
\hline \multirow{2}{*}{$\begin{array}{c}\text { Location } \\
2\end{array}$} & 1 & 0.110 & 153 & 0.0773 & 310 \\
\cline { 2 - 6 } & 2 & 0.111 & 151 & 0.0750 & 330 \\
\cline { 2 - 6 } & 3 & 0.107 & 162 & 0.0750 & 330 \\
\hline \multicolumn{3}{|c|}{ AVERAGE } & $\mathbf{1 5 5 . 3}$ & AVERAGE & $\mathbf{3 2 3 . 3}$ \\
\hline
\end{tabular}

Tab. 1. Microhardness test results

\subsection{Microstructure testing}

Microstructure testing is carried out on the not used heater as well as on the one which has been damaged during exploitation. Testing results are shown in Figure 4.

From the microstructure testing result analysis it can be concluded that the applied forming process induces a considerable transformation of the structure of the used material, i.e., austenitic $\mathrm{Cr}-\mathrm{Ni}$ steel grade W. Nr. 1.4571. In fact, the sample of the base material (pipe) has the characteristic austenitic microstructure, while the sample of the heater (cold formed pipe) is in essence structurally different with the insight presence of the deformation induced martensite. Formation of the deformation induced martensite cold hardening phenomena has a very adverse effect on the material toughness and leads to brittleness.

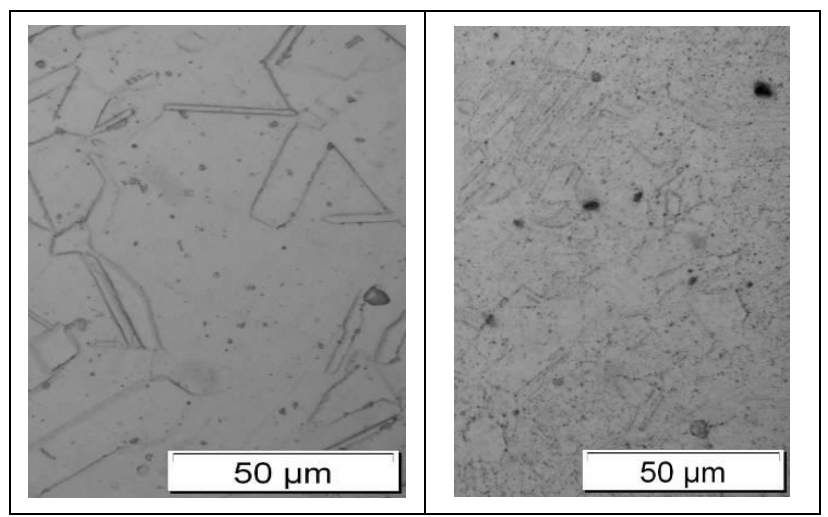

Fig. 4. Characteristic single phase austenitic structure of the base material - pipe (left) and microstructure of the heater formed pipe: the deformation induced martensite is visible (right)

\subsection{Ductility testing}

Ductility testing applying bend method was carried out on the samples of the base material - pipe and on the samples of the formed heater - cold formed pipe.

From the testing results it is visible that elongation at formed heater has considerably decreased and material has become rather brittle as compared to base material (pipe) which has, for austenitic stainless steels, typically high elongation, Figure 5.

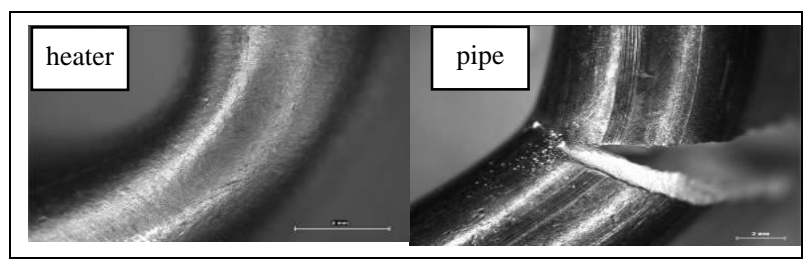

Fig. 5. Ductility testing results

\subsection{SEM}

Testing of the characteristic cracks induced on the heater during exploitation with scanning electronic microscope (SEM) additionally confirmed that material cracking appears aloof from the main crack too, figure 6.

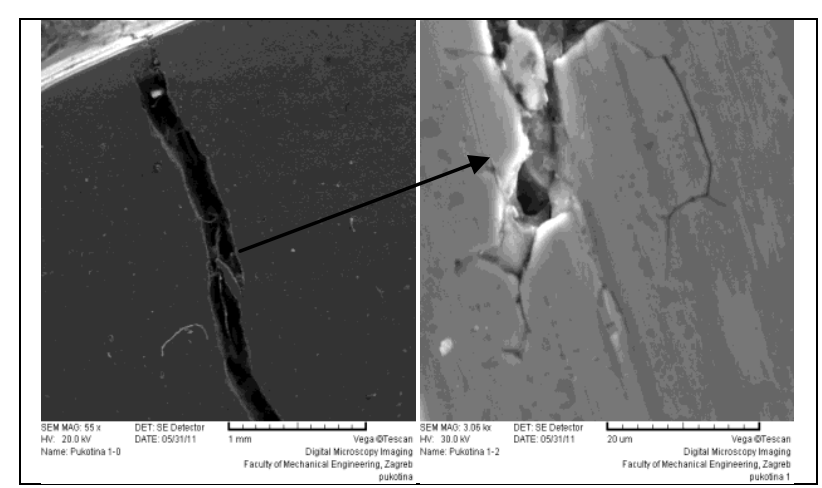

Fig. 6. SEM images of the cracking area registered on the heater during exploitation. Beside the main crack, the cracking of the material in the nearby zone is also visible.

\section{CONCLUSION}

Stainless Cr-Ni steels with austenitic structure have a very wide application thanks to their good mechanical properties, corrosion resistance properties, weldability etc. However, because of potential unexpected hardening due to cold forming and deformation induced martensite appearance some unwanted consequences - brittleness, fractures and reduced corrosion resistance are possible. That is the reason why it is important to ensure stringent quality controls of every phase of the production process when manufacturing structures made of these materials.

\section{REFERENCES}

Davis, J. R. (1994). Stainless Steels, ASM International, ISBN 0-87170-503-6, Ohio

Kurc, A.; Stoklosa, Z. (2010). The effect of $\left(\gamma \rightarrow \alpha^{\prime}\right)$ phase transformation on microstructure and properties of austenitic Cr-Ni steels. Archives of Materials Science and Engineering, Vol. 41, No. 2, (February 2010), 85-94

Meszaros, I.; Prohaszka, J. (2005). Magnetic investigation of the effect of $\alpha$-martensite on the properties of austenitic stainless steel. Journal of Materials Processing Technology, Vol. 161, 162-168

Sedriks, A. J. (1996). Corrosion of Stainless Steels, A WileyInterscience Publication, John Wiley \& Sons, ISBN: 0-47100792-7, USA

Ozgowicz, W.; Kurc, A.; Kciuk, N. (2010). Effect of deformation-induced martensite on the microstructure. Mechanical properties and corrosion resistance of X5CrNi18-8 stainless steel. Archives of Materials Science and Engineering, Vol. 43, No. 1, (May 2010), 42-43 